\title{
Retention and Transfer from Trigonometry to Physics
}

\author{
Darryl J. Ozimek, Paula V. Engelhardt, Andrew G. Bennett", N. Sanjay Rebello \\ Department of Physics, 116 Cardwell Hall, Kansas State University, Manhattan KS, 66506 \\ \#Department of Mathematics, 138 Cardwell Hall, Kansas State University, Manhattan, KS 66506
}

\begin{abstract}
We examined the extent to which students retained and transferred various concepts from trigonometry to physics at the introductory college level. Online trigonometry homework assignments and pre- and post-instruction surveys in physics were our sources of data. Transfer was measured from a traditional as well as two contemporary perspectives. Students seemed to have more difficulty retaining and transferring the unit circle concept compared to others. Transfer was more evident when measured from some contemporary perspectives rather than a traditional perspective.
\end{abstract}

Keywords: physics education research, transfer of learning. PACS: 01.40Fk

\section{INTRODUCTION}

Retention and transfer of learning are topics of interest for many educational researchers. There has been no significant prior research on retention and transfer from trigonometry to physics. The following research questions examine these issues.

1. To what extent do students retain their knowledge from trigonometry to physics?

2. To what extent do students transfer their knowledge from trigonometry to physics?

\section{RELEVANT LITERATURE}

Retention is the extent to which one can retrieve information from long term memory. The success of retrieval depends upon effective encoding that involves making associations with existing knowledge that can facilitate future retrieval. [1]

Transfer is the extent to which one can apply what was has learned in one situation to a new situation. Traditionally transfer has been measured by examining whether students can successfully apply what they have learned to new isomorphic problems. [2] Contemporary perspectives have expanded this view. Bransford and Schwartz [3] view transfer in terms of "preparation for future learning" (PFL). They focus on whether students can learn to problem-solve in a new context. Lobato's [4] "actor-oriented transfer" (AOT) model views transfer as the "personal construc- tion of similarities" between the two contexts. She focuses on how the "actors" (or learners) see the two contexts as similar.

Trigonometry concepts can be understood and applied at different levels depending upon the problem context. Van Hiele [5] used a hierarchical system of levels to describe student understanding in geometry. Trigonometric concepts (sine, cosine, tangent and their relationships) have been described in terms of three Van Hiele Levels (VHLs) of understanding:

- VHL-I (Geometric): Relationships between the sides and angles of a right triangle.

- VHL-II (Unit Circle): Relationships between the angle of an arc of a circle and its projections.

- VHL-III (Function): As functions plotted on a 'f(x) vs. x' graph.

\section{METHODOLOGY}

Students in this study were enrolled in an algebrabased physics course and had previously taken a trigonometry course at Kansas State University. We used two sources of data:

(i.) Online homework assignment scores averaged over number of attempts in the trigonometry course.

(ii.) Scores on a multiple-choice survey containing mathematics and physics questions that required knowledge of trigonometry concepts. 
The survey was given on the first day of the physics course (pre-instruction) and again after they had completed the relevant topics (post-instruction) in the course. The survey contained 18 multiple-choice questions, organized into three groups - one for each VHL. Each group contained 'abstract' questions that tested trigonometry concepts devoid of a physics context paired with 'contextual' questions that required students to apply trigonometry concepts in a physics context. Figure 1 shows an 'abstract' question and an isomorphic 'contextual' question.

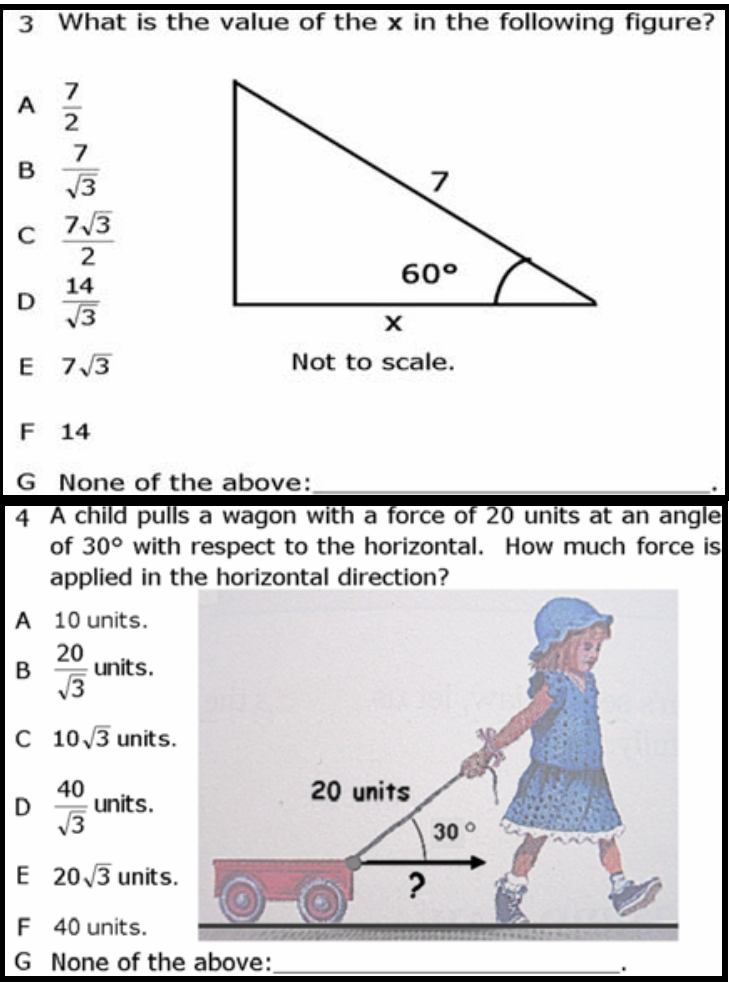

FIGURE 1. An 'abstract' (math) VHL-I question and its 'contextual' (physics) isomorphic question.

\section{Research Q \# 1: Retention}

Student scores on the pre-instruction survey for the 'abstract' questions for each VHL were used to assess retention. We did not consider the 'contextual' physics questions because these questions require students to apply their knowledge in a new context and therefore measure transfer rather than retention. To account for the fact that a concept (VHL) that was not initially learned will not be retained, we divided the preinstruction math score with the online homework score for that VHL. Thus, our retention metric was:

$$
\text { Retention }=\frac{\text { 'Abstract' (Math) Score on Pre - Survey }}{\text { Online Trig Score per Attempt }}
$$

\section{Research Q \# 2: Transfer}

Transfer was examined from a 'traditional' and two 'contemporary' perspectives (PFL and AOT). Each perspective carries a set of criteria and uses different measurements as summarized in Table 1.

TABLE 1: Perspectives of Transfer

\begin{tabular}{|c|l|l|}
\hline $\begin{array}{c}\text { Perspec- } \\
\text { tive }\end{array}$ & \multicolumn{1}{|c|}{$\begin{array}{c}\text { Criteria for } \\
\text { transfer }\end{array}$} & $\begin{array}{c}\text { Measure of trans- } \\
\text { fer in this study }\end{array}$ \\
\hline $\begin{array}{c}\text { 'Tradi- } \\
\text { tional' }\end{array}$ & $\begin{array}{l}\text { Apply knowledge } \\
\text { learned in a prior } \\
\text { context to solve a } \\
\text { problem in a new } \\
\text { context. }\end{array}$ & $\begin{array}{l}\text { Correlation between } \\
\text { online trig score per } \\
\text { attempt and 'contex- } \\
\text { tual' physics score in } \\
\text { pre/post survey. }\end{array}$ \\
\hline $\begin{array}{c}\text { 'Contem- } \\
\text { porary' } \\
\text { PFL }\end{array}$ & $\begin{array}{l}\text { Apply knowledge } \\
\text { learned in a prior } \\
\text { context to learn to } \\
\text { solve problems in } \\
\text { a new context. }\end{array}$ & $\begin{array}{l}\text { Correlation between } \\
\text { online trig score per } \\
\text { attempt and gains in } \\
\text { 'contextual' physics } \\
\text { questions. }\end{array}$ \\
\hline $\begin{array}{c}\text { 'Contem- } \\
\text { porary' } \\
\text { AOT }\end{array}$ & $\begin{array}{l}\text { Recognize rela- } \\
\text { tions of similarity } \\
\text { between the two } \\
\text { contexts. }\end{array}$ & $\begin{array}{l}\text { Correlations between } \\
\text { 'abstract' and 'con- } \\
\text { textual' scores on the } \\
\text { same survey. }\end{array}$ \\
\hline
\end{tabular}

\section{'Traditional' Perspective}

From the 'traditional' perspective transfer is measured as the ability to apply knowledge learned in a prior situation to a new situation. Transfer can be measured by comparing performance in the new situation (physics) with performance in the situation in which the knowledge was learned (trigonometry). We calculated correlations between students' online trigonometry scores with their scores on the 'contextual' physics problems on the pre- and post-instruction surveys at the same VHL. A statistically significant correlation between the average online trigonometry score and the average score on the physics survey questions at the same VHL was considered evidence of transfer.

\section{‘Contemporary’ Perspective \# 1: PFL}

The 'contemporary' PFL perspective focuses on whether students' initial learning prepares them to learn how to problem-solve in a new context. In this study we examined whether students learning in a trigonometry course prepared them to learn physics. As per the PFL perspective we calculated correlations between students' online trigonometry scores and gains (pre- vs. post-instruction) on the 'contextual' physics scores at the same VHL. The rationale for using gains is that they are a measure of learning in the physics context. Thus, using gains to measure transfer is consistent with the PFL perspective which views transfer as the ability to learn in the new context. 


\section{'Contemporary’ Perspective \# 2: AOT}

In the 'contemporary' AOT perspective, evidence of transfer is found when students create 'relations of similarity' between two situations, i.e. when they notice that two situations are similar in some way. As per this perspective we detect transfer through correlations between student performances on questions on the same survey. The fact that students' performance on two questions is significantly correlated implies that these questions have something similar about them from the students' perspective. This studentcentered notion of perceived similarity is considered sufficient evidence of transfer.

As per the AOT perspective we calculated correlations between scores on the 'abstract' (math) and isomorphic 'contextual' (physics) questions at the same VHL on the same (pre- and post-instruction) survey. The rationale for using correlations between 'abstract' and 'contextual' question is that the degree of correlation between scores on an 'abstract' (math) problem and an isomorphic 'contextual' (physics) problem is a measure of the similarities perceived by students between these two problems.

\section{RESULTS \& DISCUSSION}

\section{Research Q\# 1: Retention}

To examine retention we used the metric described in equation (1) to calculate a retention score for each student at each VHL. The average $(n=38)$ retention scores for each VHL are shown in Figure 2.

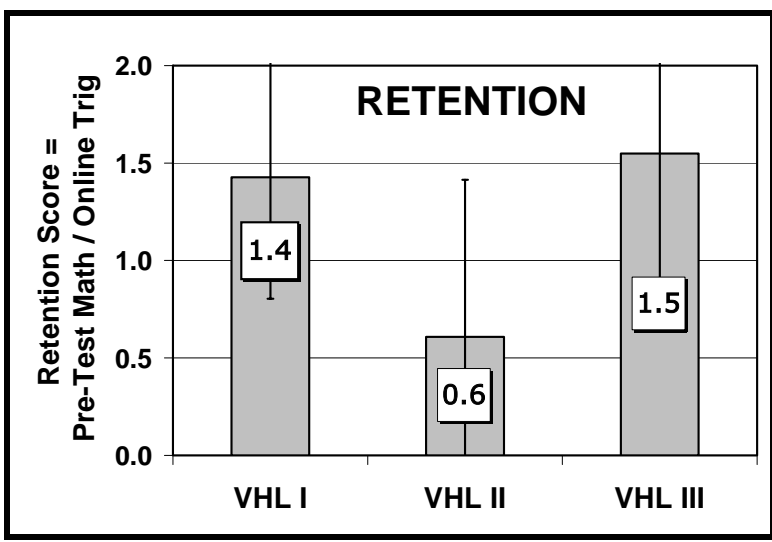

FIGURE 2: average retention scores $(\mathrm{n}=38)$ for each VHLcalculated as per equation (1).

Students appear to have greater difficulty retaining VHL-II concepts than VHL-I and VHL-III concepts.
Differences between VHL-II and VHL-I or VHL-III at the $\mathrm{p}<0.02$ significance level were detected. These results appear to indicate that the unit circle concept in trigonometry is more difficult for students to retain than the geometric or function concepts.

\section{Research Q \# 2: Transfer}

As summarized in Table 1, transfer was analyzed using multiple perspectives. We describe below our results from each perspective.

\section{'Traditional' Perspective}

As per the 'traditional' perspective, we calculated correlations between average scores on online trigonometry assignments and scores on the 'contextual' physics questions (pre- and post-instruction survey) at each VHL. No statistically significant correlations were found at any of the VHLs for either the pre- or the post-instruction survey. Thus, no evidence of transfer was found from the traditional perspective.

\section{'Contemporary’ Perspective \# 1: PFL}

As per the PFL perspective, we calculated correlations (Table 2) between the gains (post-instruction pre-instruction) on the physics survey at each VHL with the scores on online trigonometry assignments at the same VHL.

TABLE 2: Measuring transfer as from the 'contemporary' PFL perspective

\begin{tabular}{|c|c|c|}
\hline \multicolumn{3}{|c|}{$\begin{array}{c}\text { Correlation between } \\
\text { Physics Gain \& Online Trigonometry Scores } \\
(\mathrm{n}=31)\end{array}$} \\
\hline & $\mathbf{r}$ & $\mathbf{p}<$ \\
\hline VHL-I & $\mathbf{0 . 3 6}$ & 0.05 \\
\hline VHL-II & 0.13 & Not Significant \\
\hline VHL-III & -0.15 & Not Significant \\
\hline
\end{tabular}

A statistically significant $(\mathrm{p}<0.05)$ correlation (0.36) was found only for VHL-I. Thus, as per the PFL perspective, it appeared that students successfully transferred their learning at the geometric level (VHLI), but not at the unit circle level (VHL-II) or the functional level (VHL-III).

\section{‘Contemporary’ Perspective \# 2: AOT}

As per the AOT perspective, we calculated correlations (Table 3) between 'abstract' (math) and 'contex- 
tual' (physics) questions on the same survey for both the pre-instruction and post-instruction surveys.

TABLE 3: Measuring transfer from the 'contemporary' AOT perspective

\begin{tabular}{|c|c|c|c|c|}
\hline \multicolumn{5}{|c|}{$\begin{array}{c}\text { Correlations between } \\
\text { 'abstract' (math) \& 'contextual' (physics) } \\
\text { scores on the same survey }\end{array}$} \\
\hline & \multicolumn{2}{|c|}{$\begin{array}{r}\text { Pre-Survey } \\
(\mathrm{n}=43)\end{array}$} & \multicolumn{2}{c|}{$\begin{array}{c}\text { Post-Survey } \\
(\mathrm{n}=40)\end{array}$} \\
\hline & $\mathbf{r}$ & $\mathbf{p}<$ & $\mathbf{r}$ & $\mathbf{p}<$ \\
\hline VHL-I & $\mathbf{0 . 7 9}$ & 0.001 & $\mathbf{0 . 5 3}$ & 0.001 \\
\hline VHL-II & -0.01 & Not Sig. & 0.20 & Not Sig. \\
\hline VHL-III & $\mathbf{0 . 7 6}$ & 0.001 & $\mathbf{0 . 3 9}$ & 0.05 \\
\hline
\end{tabular}

Statistically significant correlations were found for VHL-I and VHL-III on both the pre- and postinstruction surveys. Thus, as per the AOT perspectives, it appeared that students were able to dynamically transfer their knowledge from the 'abstract' (math) to the 'contextual' physics questions for VHLI (geometric) and VHL-III (function), but not for VHL-II (unit circle).

\section{CONCLUSIONS}

\section{Research Q \# 1: Retention}

Our retention results indicate that students had a significantly greater retention of the geometric and function concepts in trigonometry compared to the unit circle concept. The results are also anomalous with the assumption of hierarchical VHLs.

\section{Research Q \# 2: Transfer}

As expected, the perspective of transfer that we adopted directly influenced whether we found evidence of transfer. We did not find any evidence of transfer from trigonometry to physics as per the 'traditional' perspective. However, when we broadened our perspective we found evidence of transfer as per the 'contemporary' PFL and AOT perspectives. We believe that this observation is not a weakness of our study; rather it underscores the importance of examining transfer from a variety of different perspectives.

Transfer was also found to be non-uniform across VHLs. Stronger evidence of transfer was detected for VHL-I (geometric) concepts than for VHL-III (function) concepts, and none was detected for VHL-II (unit circle) concepts.
Table 4 summarizes the retention and transfer results. Each check mark indicates evidence of transfer or retention. These results appear to converge on the conclusion that students have most difficulty in both retaining and transferring the unit circle concept (VHL-II).

TABLE 4: Summary of Results

\begin{tabular}{|c|c|c|c|}
\hline VHL & I & II & III \\
\hline Retention & $\checkmark$ & & $\checkmark$ \\
\hline 'Traditional' Transfer & & & \\
\hline 'Contemporary' PFL Transfer & $\checkmark$ & & \\
\hline 'Contemporary' AOT Transfer & $\checkmark$ & & $\checkmark$ \\
\hline
\end{tabular}

\section{FURTHER RESEARCH}

Our results appear to be anomalous with the hierarchical nature of VHLs. Therefore, further research is necessary to analyze the nature of trigonometry knowledge, especially when applied in the context of physics.

We speculate that student difficulties with the unit circle concept are probably because they did not use this concept extensively in their trigonometry course. They completed only two online assignments on the unit circle compared with four assignments on the function concept. Further research will be necessary to investigate these speculations.

\section{ACKNOWLEDGMENTS}

Work funded in part by NSF grant DUE-0206943.

\section{REFERENCES}

1. Sousa, D.A., How the Brain Learns. $2^{\text {nd }}$ ed. 2000, Thousand Oaks, CA: Corwin Press, Inc.

2. Reed, S.K., G.W. Ernst, and R. Banerji, The role of analogy in transfer between similar problem states. Cognitive Psychology, 1974. 6: p. 436-450.

3. Bransford, J.D. and D. Schwartz, Rethinking transfer: A simple proposal with multiple implications. Review of Research in Education, 1999. 24: p. 61-100.

4. Lobato, J.E., How Design Experiments Can Inform a Rethinking of Transfer and Vice Versa. Educational Researcher, 2003. 32 (1): p. 17-20.

5. Van Hiele, P.M., Structure and insight: A theory of Mathematics Education. 1986, Orlando, FL: Academic Press. 